\title{
O estilo lacaniano e a polissemia dos conceitos
}

\author{
Flávio Fernandes Fontes $\star$ \\ Universidade Federal do Rio Grande do Norte, Natal, RN, Brasil
}

Resumo

\begin{abstract}
O estilo de Lacan não é um simples envoltório do pensamento, mas sim algo essencial para a sua proposta de transmissão da psicanálise. Procuramos analisar uma de suas principais características: a polissemia conceitual. Para isso utilizamos principalmente o trabalho de comentadores como Milán-Ramos e Beividas, com o objetivo de realizar uma discussão entre dois tipos ideais antagônicos: a transmissão subjetiva e a transmissão cientifica. Levantamos os problemas e vantagens de cada ponto de vista, reconhecendo os seus limites na tentativa de melhor compreender a psicanálise, que acaba transcendendo a categorização em Arte ou Ciência.
\end{abstract}

Palavras-chave: Lacan; estilo; transmissão.

\section{The lacanian style and the polysemy of the concepts}

\begin{abstract}
The Lacanian style is not a simple envelopment of thought but something essential to his proposal of the transmission of psychoanalysis. We analyze one of its main features: the conceptual polysemy. For this task we utilize mainly the work of commentators such as Milán-Ramos and Beividas, in order to make a discussion between two opposing ideal types: the subjective transmission and the scientific transmission. We discuss the problems and advantages of each point of view, recognizing its limits in the attempt to better comprehend psychoanalysis, that ends up transcending the categorization in Art or Science.
\end{abstract}

Keywords: Lacan; style; transmission.

Uma das concepções possíveis de estilo é aquela em que ele é entendido como um envoltório do pensamento, a forma de um determinado conteúdo (ENKVIST, 1974). No entanto, dentro do contexto de transmissão da psicanálise lacaniana, o estilo tende a significar outra coisa; ele é o próprio conteúdo a ser transmitido. É possível ler nessa característica um reflexo coerente com a postura de Lacan e o papel decisivo da sua influência:

Qualquer retorno a Freud que dê ensejo a um ensino digno deste nome só se produzirá pela via mediante a qual a verdade mais oculta manifesta-se nas revoluções da cultura. Essa via é a única formação que podemos pretender transmitir àqueles que nos seguem. Ela se chama: um estilo (LACAN, 1998a[1957], p. 460).

O papel predominante do estilo é uma tendência que claramente se acentua ao longo do seu ensino, que começa com textos redigidos de forma mais próxima da tradicional, mas que, ao longo dos anos, vão se tornando cada vez mais idiossincráticos, desenvolvendo uma linguagem particular.

O estilo como uma forma que deve ser domada para uma adequada comunicação de um conteúdo (modo de transmissão científico) e o estilo como indomável expressão do sujeito (modo de transmissão subjetivo) são os dois extremos que utilizamos como referência nesse artigo. Trata-se de dois tipos ideais, mas que podem ser úteis justamente enquanto representativos de dois polos - assim como há entre o preto e o branco infinitos tons de cinza, certamente há infinitas modulações entre o estilo que busca univocidade absoluta (científico) e o que dá plena vazão à equivocidade da polissemia (subjetivo).

^Endereço para correspondência: Rua Jaguarari, nº 4980, casa 44, Candelária, Natal/RN.E-mail: flaviofontes@outlook.com
É a partir do embate entre esses dois tipos ideais que iremos interrogar quais as possíveis interpretações para aquilo que entendemos ser um dos traços principais do estilo lacaniano na transmissão da psicanálise: a polissemia dos conceitos, isto é, o fato de que os conceitos têm múltiplos significados. Em seguida faremos considerações sobre como a discussão sobre o estilo de transmissão pode nos ensinar sobre o lugar epistemológico da psicanálise.

\section{A polissemia dos conceitos: riqueza ou inconsistência?}

Tudo se passa "como se os conceitos psicanalíticos, antes de achar seu lugar na teoria, devessem mexer, deslocar alguma coisa no sujeito" (MILÁN-RAMOS, 2007, p. 14). Nada mais natural, portanto, que pouca atenção seja dada à definição clara dos termos, eliminação de ambiguidades, delimitação rigorosa do sentido das palavras utilizadas - tudo aquilo que uma transmissão científica tradicionalmente exige e preza.

Sob certo ponto de vista, Lacan é justamente o contrário de um pensador que constrói um sistema, seu seminário é uma investigação errática, uma eterna digressão que não teme inventar novos conceitos, rever o que já foi dito sob outro prisma e seguir sempre adiante, sem preocupação de ordenar o percurso em uma seqüência lógica.

Ao contrário, se o discurso lacaniano tem a pretensão de imitar o próprio inconsciente nas suas reviravoltas, na sua polissemia e imprevisibilidade, ele tem que ser volátil, metamorfoseando-se em um jogo de espelhos que remeta à cifração e ao desvelamento do desejo do sujeito. "O estilo lacaniano mostra a entrada no desfiladeiro de uma experiência de subjetivação" (MILÁN-RAMOS, 2007, p. 19). Podemos dizer que se trata de um convite 
direcionado ao sujeito no que ele tem de mais singular e pessoal, seu desejo, seu inconsciente, sua posição subjetiva diante do saber e do conhecimento.

Milán-Ramos (2007, p. 36) aponta a existência de "uma certa recusa à definição dos conceitos" na teoria lacaniana: "sempre que for possível, sempre que parecer viável, evitar o avanço do texto como um encadeamento dedutivo a partir de definições: poupar-nos dessa cristalização do tempo da teoria que se encarna na certeza e na segurança das definições".

Esse procedimento, que, segundo Milán-Ramos (2007, p. 37), Lacan chamou de "fracasso do conceito", é obviamente um fracasso deliberado para que "a letra perca estabilidade e apele ao significante [...] e a subjetivação da letra possa produzir-se". O que isso quer dizer é que a falta de clareza nas definições, ou melhor, a indefinição deliberada, é justamente o recurso escolhido para que se abra as portas da subjetivação do texto.

O labirinto da teoria é construído para que o sujeito tenha que se haver com a sua parte na produção do sentido, e tenha uma participação ativa na invenção da psicanálise, conquistando o seu entendimento com base na sua experiência e esforço, contra os obstáculos que lhe interpõe a selva dos significantes e descobrindo inclusive o sem-sentido da experiência do Real.

Desnecessário dizer que estamos muito longe das formas de discurso tradicionais da ciência, onde a clareza e coerência dos raciocínios devem buscar um único entendimento, onde se procura o sentido unívoco, e não equívoco. No entanto, paradoxalmente, a teoria lacaniana brinca insistentemente com o discurso científico, e podemos dizer que em alguns momentos se passa por ele, faz semblante de ciência, na medida em que recorre à matemática, à lingüística, à lógica, se revestindo do prestígio dessas disciplinas para falar de outra coisa (o inconsciente) e subvertê-las de forma irônica.

Como um exemplo dessa ironia citamos Milán-Ramos (2007, p. 43), que chega a dizer que "certo efeito tautológico sempre resulta produtivo na hora de construir definições" e celebra a frase de Lacan "um significante representa um sujeito para outro significante" como exemplo disso. Nesse caso, o procedimento lacaniano é justamente o contrário do que ensina a disciplina da lógica, que entende que a tautologia na definição é uma falha que torna a definição inútil, pois não se pode definir um termo utilizando ele mesmo - no caso não se pode dizer que um significante é aquilo que representa um sujeito para outro significante, pois o termo "significante" é justamente aquilo que deveria ser definido. Dentro da estratégia da transmissão subjetiva, no entanto, essa falha lógica é que deve ser estimulada: "A psicanálise rejeita o brilho do sucesso das definições, porque reconhece na linguagem uma dimensão essencial do fracasso do conceito" (MILÁN-RAMOS, 2007, p. 43).

"A ambigüidade da letra é o espaço no qual a letra se abre aos efeitos do significante, aguarda seus efeitos subjetivantes e, concomitantemente, é o espaço no qual seu endereçamento pode produzir efeitos subjetivantes"
(MILÁN-RAMOS, 2007, p. 56). Podemos dizer que toda essa estratégia da transmissão subjetiva tem funcionado muito bem, de forma coerente com seus pressupostos e objetivos declarados, como demonstra a crescente literatura em torno do tema da psicanálise lacaniana e o caso específico de Milán-Ramos pode ser apontado como um ótimo exemplo de leitor que se envolveu dessa forma com a obra de Lacan.

Por outro lado, examinemos esse desprezo pelas definições sob o ponto de vista da transmissão científica. Para esta, a idéia básica para que existam conceitos é que ao utilizar uma determinada palavra dentro de uma comunidade de falantes se obtenha um efeito parecido em todos os ouvintes, de modo a fazer com que haja compreensão sobre o que se está falando. Esse é o objetivo das definições e por isso existe preocupação a respeito de sua precisão.

O temor é que, sem o cuidado necessário com essa precisão, um determinado autor corre o risco de falar sobre algo sem que haja um acordo de entendimento básico com seus ouvintes acerca dos termos que estão sendo utilizados. Ou seja, pode-se falar e conversar sem que ninguém saiba ao certo o que está sendo dito, o que torna essa comunicação imprevisível e virtualmente sem sentido. Para a mentalidade científica é preciso saber muito bem do que se está tratando em cada momento, caso contrário nenhuma comunicação verdadeira é possível.

Crença oposta àquela que rege a comunidade lacaniana: a de que a essência da comunicação é o mal-entendido. Para a ciência, o mal-entendido não é a regra, é a exceção que deve ser combatida, extirpada. A ambigüidade e a polissemia precisam ser tanto quanto possível eliminadas de qualquer comunicação científica. Exemplificaremos essa mentalidade científica citando trechos do manual de estilo da American Psychological Association (APA) que ilustram bem esse combate:

Diga apenas o que precisa ser dito [...] descarte descrições excessivamente detalhadas [...] adornos desnecessários; elaborações em torno do óbvio; observações ou apartes irrelevantes [...] certifique-se de que todas as palavras significam o que você pretende dizer [...] evite expressões coloquiais, que dispersam o significado [...] Os recursos que atraem a atenção para palavras, sons, etc. em vez de para idéias, são inadequados na escrita científica. Evite o uso excessivo de aliteração, de rima, de expressões poéticas e de clichês. Use metáforas moderadamente; embora elas possam contribuir para simplificar idéias complicadas, podem também distrair o leitor. Evite usar metáforas mistas (por exemplo, uma teoria que representa um ramo de um crescente corpo de evidências) e palavras com significados adicionais ou indesejáveis, que podem distrair ou de fato enganar o leitor. Use expressões figuradas com moderação e expressões pitorescas com cuidado (APA, 2006, p. 19$21 ;$ p. 41, grifo do autor).

Essas recomendações condenam várias práticas que são frequentes no estilo lacaniano, dentre elas o uso de recursos literários e metáforas: "Os próprios escritos de Lacan transbordam de metáforas extravagantes, absurdas 
e mistas, precisamente para tirar o leitor de um reducionismo complacente inerente a todo processo de compreensão" (FINK, 1998, p. 95).

Não é preciso procurar muito para ver que as metáforas e a escrita com expressões poéticas aparecem constantemente nos trabalhos dos psicanalistas do campo. Algumas expressões colhidas por Beividas (2006, p. 391), sem citar os autores, foram “a pulsão é uma comichão, uma cócega que, vira-e-mexe, faz balancê", ou "a neurose é a captura da subjetividade pelo enigma tornado voragem". Outro exemplo, que tomamos de Žižek (1997, p. 224) é: “Uma das definições do real lacaniano é que ele é o corpo esfolado, escalpelado, a palpitação da carne vermelha, viva".

A postura científica, no entanto, não é a de proibir absolutamente as metáforas, mas sim a de defender que elas não podem ser utilizadas em substituição de definições teóricas. Devem ser usadas "moderadamente":

Sem contestar a metáfora ou o poético como legítimos instrumentos de captação e de formulação dos fenômenos sutis da linguagem e, portanto, do psiquismo, apenas a sua proliferação, sem o lastro de uma demonstração consistente, pode até confortar uma ou outra veleidade poética, mas não otimiza a produção nem a transmissão da teoria (BEIVIDAS, 2006, p. 397).

Para uma transmissão científica é inadmissível o uso indiscriminado de metáforas do tipo o Outro como um "tesouro dos significantes" o real como "um furo" etc. Tais expressões são vistas como um abuso que tomou o lugar da verdadeira construção teórica, afinal, metáforas podem ajudar a transmitir um conceito, criar uma imagem que facilite sua compreensão, mas devem poder ser traduzidas em formulações teóricas claras. Se isso não acontece, o que restaria é apenas um uso indiscriminado de metáforas, que pode ser algo interessante para o discurso poético, mas é extremamente frágil e impreciso dentro de uma teoria que se pretende rigorosa.

A partir do ponto de vista científico, se pode condenar do mesmo modo a prática dos aforismos, pelo que eles possuem de imprecisos. O efeito das máximas lacanianas é que a falta de explicações unívocas e precisas faz com que cada um interprete o sentido da frase de uma maneira diferente, fazendo do termo teórico um verdadeiro leque de possibilidades que se expandem em várias direções de forma imprevisível.

Com a valorização da transmissão subjetiva dentro do campo lacaniano, podemos dizer que o procedimento usual é fazer com que os conceitos sejam introduzidos sem definição tradicional. São mais frequentemente utilizados em ato e se espera que o ouvinte/leitor em algum momento "entenda" o que tal conceito é através da repetição e do uso continuado, que a construção do sentido dos conceitos seja algo relativo ao percurso de cada um na sua vivência da psicanálise.

São frases e termos que oferecem uma margem de interpretação extremamente alta, e é esperado que o leitor os preencha de sentido. Como colocou o próprio Lacan (1998[1966], p. 11) na abertura dos Escritos: “queremos, com o percurso de que estes textos são os marcos e com o estilo que seu endereçamento impõe, levar o leitor a uma consequência em que ele precise colocar algo de si".

Um autor que parece estar mais consciente dos múltiplos sentidos dos termos na teoria lacaniana é Fink, e é interessante observar o que ele tem a dizer: "Nas minhas primeiras obras sobre Lacan, eu estava bastante preocupado em compreender as 'verdadeiras distinções' entre o Nome-do-Pai, S(A), $\Phi$, S1, e assim por diante, e seus sentidos e usos múltiplos me incomodavam" (FINK, 1998, p. 180).

Fink continua contando como se permitiu superar tal incômodo e refletir livremente sobre os conceitos interpretando-os da forma como lhe parecia ser mais adequado de acordo com cada contexto. Ou seja, ele aprendeu a reconhecer que não existem as 'verdadeiras distinções' entre os termos, porque seus sentidos não estão fixos, presos por definições, sendo o uso esperado dos termos dentro da comunidade lacaniana esse que Fink aprendeu com o tempo: usá-los conforme o momento, dentro do contexto, e de acordo com a subjetividade interpretativa.

Apesar desse relato de mudança de atitude por parte de Fink, notamos que o propósito de distinguir entre diferentes significados de forma mais clara nunca abandonou sua abordagem de Lacan. Encontramos Fink (1998, p. 31) distinguindo, por exemplo, 4 faces diferentes do conceito de Outro a partir de sua leitura de Lacan: 1) o Outro como linguagem, conjunto de todos os significantes; 2) o Outro como demanda; 3) o Outro como desejo (objeto a) e 4) o Outro como gozo. Em outro momento do mesmo livro (FINK, 1998, p. 43-47) fala do real como 1) referente a um tempo anterior a linguagem; 2) como sinônimo do que ainda não foi simbolizado; 3 ) como trauma; 4) e como algo gerado pela dinâmica interna da ordem simbólica.

Isso demonstra a prática comum de colocar vários significados em um mesmo termo, com a notável diferença de que Fink parece muito mais atento e consciente disso do que a maioria dos autores lacanianos, e o expressa de forma mais aberta. Fink (2004, p. 143) fala sobre dois tipos de sujeito na obra de Lacan: o sujeito do significante e o sujeito do gozo - para em seguida lamentar que Lacan raramente especifica sobre qual sujeito ele está falando em um dado momento!

Os próprios matemas, que à primeira vista poderiam parecer esforços de fornecer formalizações precisas da experiência analítica, são objetos de diferentes interpretações e utilizações: "Os sentidos dos símbolos muitas vezes mudam de forma significativa no curso dos textos de Lacan" (FINK, 1998, p. 143) e "Cada matema condensa e corporifica, em um certo sentido, uma quantidade considerável de conceitualizações, embora cada um seja também altamente polivalente" (FINK, 1998, p. 177). A transmissão subjetiva vê essa polissemia como uma riqueza da obra de Lacan, enquanto os adeptos da transmissão científica apontam-na como um profundo defeito. 


\section{Críticas do modo de transmissão científico ao estilo lacaniano}

Um dos exemplos mais destacados de polissemia se encontra no conceito de objeto a:

Ao criar o objeto a, Lacan sentiu que havia feito a contribuição mais importante à psicanálise. Poucos conceitos na obra lacaniana foram elaborados de forma tão ampla, revistos de maneira tão significativa da década de 1950 à década de 1970, examinados em minúcias a partir de perspectivas muito diferentes, e exigem tantas modificações em nossa forma habitual de pensar o desejo, a transferência, e a ciência. E poucos conceitos têm tantos avatares nas obras de Lacan: o Outro, o agalma, o número de ouro, a Coisa Freudiana, o real, a anomalia, a causa do desejo, o mais-gozar, a materialidade da linguagem, o desejo do analista, a consistência lógica, o desejo do $\mathrm{Ou}$ tro, o semblante/simulacro, o objeto perdido e assim por diante. Uma vez que literalmente milhares de páginas na obra de Lacan, a maioria delas ainda não publicadas, são dedicadas ao desenvolvimento desse conceito, não posso de maneira alguma esperar fornecer uma explicação satisfatória para o objeto a que explique ou abranja de maneira adequada todas as teorias de Lacan (FINK, 1998, p. 107).

Qual a reação diante desse estado surpreendente de complexidade/indefinição da teoria de Lacan? A reação dos discípulos parece ter sido a suposição de que devem estudar mais a fundo a obra do mestre, para chegar a uma compreensão cada vez maior do que significa o objeto a. A reação pragmática de tantos outros leitores que jogam o livro de lado é que não vale a pena se esforçar para ler um autor que é capaz de produzir milhares de páginas confusas e mal elaboradas sobre um conceito que no final ninguém sabe ao certo o que é.

Fink (1998, p. 108) continua:

Não é uma questão simples reconciliar todas as suas formulações com relação ao objeto. Sem dúvida, isso é parte do que torna o conceito tão fértil para elaborações adicionais, mas tão enervante para o sistematizador e tão entediante para 'os espíritos científicos'. Pode um conceito tão polivalente ser de algum valor para a constituição da psicanálise como um discurso significativo e principalmente como uma ciência?

Embora Fink trate do objeto a, fica claro que a reflexão remete a um questionamento mais geral: se os conceitos são tão indefinidos, pode a psicanálise lacaniana ter valor enquanto discurso logicamente coerente ou ciência? Mas, ao mesmo tempo, poderíamos perguntar: será que a psicanálise almeja qualquer um desses objetivos?

Embora de uma forma diferente, podemos dizer que a questão da linguagem e dos conceitos já era um problema da psicanálise na época de Lacan, devido à fragmentação em diversas escolas e grupos teóricos diferentes, quadro que Miller (1999) pinta habilmente como uma "babel psicanalítica". Teria o lacanismo acrescentado um estilo a mais nessa babel, estilo que consegue ser ainda mais obscuro que os anteriores?

Para Miller (1997) a dificuldade do ensino de Lacan levou muitos lacanianos a se refugiarem na obscuridade. Hoje podemos falar que houve a criação de um verdadeiro dialeto, o lacanês - também chamado por Pierrakos (2005, p. 29) de "parlacan" - uma nova linguagem da qual o mínimo que se pode dizer é que ela não prima pela clareza - vejamos um exemplo dado por Beividas (1995, p. 8):

Essa metáfora [paterna], diz um psicanalista, dá seu significante ao desejo e ao gozo barrando o A do Outro. O efeito da significação fálica inscreverá o gozo sob a forma de uma articulação que tem por consequência alíngua (lalangue). Os objetos a darão assim ao ser falante sua dimensão àquilo que se chama realidade. Esses objetos articularão o discurso, isso porque falar designa a ausência [de sentido] (ab-sens) do Outro.

Beividas (1995) prossegue dizendo que esse paragráfo "não diz nada para meu entendimento" e propõe a brincadeira de trocar vários dos conceitos de lugar uns com os outros (metáfora paterna, significante, desejo, gozo, Outro, alingua, objeto a), pois no final das contas não faria nenhuma diferença.

Afinal, dar continuidade a tal modo de lidar com os conceitos e com a experiência psicanalítica poderá levar a um obscurantismo cada vez maior por parte da comunidade lacaniana? Haverá como conseqüência um aumento do isolamento dos psicanalistas, dado a sua incompatibilidade e falta de abertura para com outros discursos? Miller (1997, p. 159) se mostra consciente desses perigos:

Como é o tipo de agrupamento ao redor dos significantes de Lacan? Na verdade nós somos uma pequena seita (...) É certo que temos a propensão de fazermos nossas próprias publicações, não compartilhamos da vida intelectual em geral. Temos de abrir as portas [...].

Beividas (2006, p. 397) constata o mesmo:

A partir da morte de Lacan, a psicanálise herdada voltou a correr o mesmo risco de solipsismo, de enclausuramento, de auto-suficiência que caracterizou os discípulos de Freud até os anos cinqüenta. Ela começa novamente hoje a se ressentir dos embaraços das meras repetições, de mimetismos ou paráfrases menores do texto de Freud e, sobretudo, de Lacan. Não consegue efetivar um diálogo mais conseqüente com a comunidade científica, em que os conceitos tenderiam a perder, na discussão crítica, o ranço do esotérico.

Miller (1997) constata com surpresa que nos encontros de psicanalistas lacanianos que tem freqüentado todos os trabalhos estão de acordo com Lacan e sugere que isso seja o efeito de uma identificação, e que esta constitui um obstáculo ao trabalho.

São dois os possíveis efeitos nocivos do uso deteriorado da linguagem: a incomunicabilidade com outros discursos da sociedade em geral é um deles e a corrosão do entendimento dentro do próprio grupo é outro, embora esse pareça bem menos perceptível, dado a aceitação geral da transmissão subjetiva e o desdém pela noção de comunicação clara. Como se poderia dizer que há um entendimento certo ou errado quando não há significado unívoco a ser percebido? Isso seria o mesmo que dizer que qualquer coisa vale? Como avaliar a qualidade de uma transmissão quando o mal-entendido é cultuado como onipresente na comunicação humana? Esses são 
alguns questionamentos que a polissemia conceitual lança para o campo lacaniano quando interpretada a partir do modo de transmissão científico.

\section{Corrente científica $x$ subjetiva e a epistemologia da psicanálise}

Tentaremos aprofundar o debate entre a corrente subjetiva e a científica nos utilizando para isso da leitura que cada um desses pontos de vista faz da polissemia conceitual, ou fenômeno da indefinição dos conceitos em Lacan. O debate que até aqui levamos adiante a partir do exame do estilo, será forçado a avançar para articular mais explicitamente também suas bases e implicações epistemológicas.

Do ponto de vista subjetivo "se tentamos separar a objetividade teórica do estilo teórico lacaniano [...] não sobra nada" (MILÁN-RAMOS, 2007, p. 47). Estilo e teoria são o mesmo, inseparáveis, e uma dose de ambiguidade e polissemia será sempre bem vista, pois estará a serviço dos efeitos de subjetivação que visam a formação do analista, que deve interpretar os textos em comunicação com sua experiência em análise, prática clínica, supervisão e produção teórica.

A polissemia conceitual não constitui um problema aqui, mas sim um instrumento para forjar um saber singular, que seja expressão do sujeito. A transmissão de um estilo e de uma ética é o que está em jogo, e para isso o estilo lacaniano é extremamente adequado, na medida em que trabalha com o desejo e com o engajamento do sujeito.

Sob a ótica científica, a pergunta que se faz é: o que restaria do pensamento de Lacan se o verniz verbal que o reveste fosse retirado ${ }^{1}$ Se o resultado for nada, então não há nenhuma utilidade (científica) em ler sua obra, e se for encontrado algo, esse conteúdo deveria ser extraído e separado do estilo que o envolve, para ser exposto dentro dos cânones da comunicação científica padrão, que visa ao entendimento mútuo.

Dentro da perspectiva científica, um programa de pesquisa extenso a ser realizado é a análise dos diferentes sentidos dos conceitos lacanianos e sua organização dentro de um sistema explícito e organizado. Não sabemos dizer em que medida isso é possível ou desejável, nem se se trata de uma tarefa condenada ao fracasso desde o início. O essencial é que para o ponto de vista científico o estilo de Lacan é um obstáculo no meio do caminho dos conceitos.

A transmissão subjetiva, no que tem de melhor, permite a liberdade da criação e a pluralidade de sentidos, a exploração dos efeitos estéticos e transferenciais; o discurso se torna um ato analítico em si mesmo, com grande apelo de convocação ao sujeito, pois tem como efeito apontar a direção do Real, na medida em que afirma a não existência da relação sexual. Por outro lado, no que tem de pior, encarna a falta de rigor e precisão a ponto de perder o significado das palavras, em um dialeto ininteligível e hermético, no qual tudo o que resta é uma conversação impossível.

\footnotetext{
Pergunta que Sokal e Bricmont (1999, p. 153) fazem a respeito de Baudrillard, mas que pode ser facilmente transposta para Lacan, enquanto representativa desse ponto de vista.
}

A transmissão científica, em seu lado positivo, permite o estabelecimento de uma linguagem comum e significados estáveis, essenciais para o progresso do conhecimento e seu ensino. A organização e sistematização levam a novos avanços e intercâmbio mais fácil com outras áreas. Em seu aspecto negativo pode se tornar uma camisa de força para a teoria, tornando os conceitos elementos imutáveis e o sistema algo fechado, aniquilando o espírito investigativo. Desestimula a relação pessoal com a teoria e o conteúdo, tratando tudo de forma fria, impessoal e asséptica, podendo gerar uma teoria morta, a ser decorada e não vivida.

Ao discutir o estilo de Freud, Souza (1999) critica a divisão feita por Walter Schönau entre prosa artística e prosa científica, divisão praticamente idêntica a que denominamos de transmissão subjetiva e científica, argumentando que vários autores desafiam essa forma de classificação, produzindo textos que questionam essas fronteiras. Freud é justamente um desses autores que não poderiam se deixar reduzir a qualquer um desses dois estilos de escrita.

Para Chaitin (1996) o discurso de Lacan é ao mesmo tempo Mythos e Logos, poesia e ciência. As palavras não podem ter um significado correto e fixo, a linguagem sempre está aberta ambiguidades: seu poder metafórico é algo que lhe é inerente e não acidental. Turkle (1992) diz que se tentarmos colocar Lacan em um lado ou outro da linha que separa ciência e poesia o que acontece é que a linha mesma passa a ser questionada.

De fato, embora o estilo subjetivo apareça de modo mais proeminente, é possível encontrar traços de ambos os modos de transmissão em Lacan. A obra de Freud, no entanto, pode ser citada como um exemplo ainda mais enfático do uso diversificado desses estilos, uma vez que nela encontramos alguns textos de cunho mais literário, outros de cunho mais científico e outros ainda mais filosóficos, especulativos (Souza, 1999). "Quantos Freud existem? Há o sagaz observador da natureza humana e, também, o cientista materialista lamarckiano do século XIX, o criador de teorias especulativas e o clínico rigoroso" (BLEICHMAR, N.; BLEICHMAR, C., 1992, p. 171).

A natureza falha e o alcance limitado dessa classificação não a impede de ter sua utilidade, ajudando a delimitar e a dizer algo da realidade discursiva em questão, tal como fizemos. Baseados no que discutimos até aqui, poderíamos pensar a psicanálise como um discurso e uma prática que possui potencial e flexibilidade para utilizar-se de vários registros diferentes do saber e da experiência humana.

O estatuto sempre complexo e problemático do seu posicionamento na história das ciências e na epistemologia ${ }^{2}$ parece revelar algo: na psicanálise os domínios da Arte e Ciência se confundem. De fato, pensar a Psicanálise como tendo participação nesses dois registros, sem se reduzir a nenhum deles, é algo que faz justiça às obras de Freud e Lacan, e escancara as dificuldades de optar de forma decisiva entre uma transmissão subjetiva e uma científica.

\footnotetext{
${ }^{2}$ Ver as dificuldades de Figueiredo (2003) para situar a psicanálise epistemologicamente.
}

Fractal, Rev. Psicol., v. 27 - n. 3, p. 324-329, 2015 


\section{Considerações Finais}

O estilo de Lacan é algo muito importante para ser tão pouco explorado nas publicações sobre psicanálise. Nos livros sobre Lacan, o mais comum é que o seu estilo ocupe um lugar de fundo, sendo mencionado enquanto algo de menor importância, como uma curiosidade, ou nem sequer seja abordado. Às vezes tem-se a impressão de que não se trata de um assunto digno de ser tratado no primeiro plano, ou que isso não faria a menor diferença para a transmissão da psicanálise.

No entanto, estilo e epistemologia estão ligados de tal forma que a epistemologia se expressa no estilo e o estilo nos conta da epistemologia. Refletir sobre o estilo é pensar qual o modo de produção de conhecimento que está em jogo, e refletir sobre a produção do conhecimento é ao mesmo tempo ter de escolher uma forma de expressão.

Procuramos enfatizar ao longo deste artigo as críticas do que denominamos de modo de transmissão científico ao estilo lacaniano, mais do que apresentar a compreensão interna que o estilo lacaniano tem de si mesmo. Isto porque o modo de transmissão subjetivo já é algo consolidado no campo de produção sobre a psicanálise lacaniana. $\mathrm{O}$ estilo lacaniano está tão enraizado dentro das produções do campo que corre o risco de ser tomado como um pressuposto não examinado.

Todo destaque que colocamos nas críticas tem assim a intenção deliberada de provocar um espanto, tentar sair do lugar comum dos textos sobre psicanálise lacaniana e atrair a atenção para o tema. Nossa posição pessoal é a de que há aspectos positivos e negativos em qualquer que seja a escolha do estilo, e que a principal lição a ser tirada dessa questão é justamente a insuficiência da dicotomia Arte x Ciência, isto é, a insuficiência de tentar reduzir tudo a uma transmissão científica ou subjetiva. No entanto, é igualmente importante levantar as tensões que existem entre esses dois modos de transmissão, e o que cada um pode aprender com o outro.

Não refletir sobre o porquê do estilo adotado e simplesmente o incorporar e passar adiante a sua forma característica de linguagem pode ser o suficiente para sua reprodução, mas não é suficiente para sua apropriação crítica. Ao utilizar qualquer estilo corremos o risco de adotar uma tradição da qual não conhecemos as origens. Acreditamos que as críticas aqui mencionadas podem servir para reflexão e esperamos que ao final desse artigo o leitor tenha mais recursos que o ajudem fazer um julgamento próprio sobre o tema. Rejeitar qualquer modo de expressão sem entender sua função e valor para os que o empregam corre o risco de ser um julgamento superficial e desinformado.

\section{Referências}

AMERICAN PSYCHOLOGICAL ASSOCIATION. Manual de estilo da APA: regras básicas. Porto Alegre: Artmed, 2006.

BEIVIDAS, W. O estilo em Lacan e a estilística pós-lacaniana. Psicologia \& Psicanálise, Rio de Janeiro, n. 6, p. 33-48, 1995.

BEIVIDAS, W. Pulsão, afeto e paixão: psicanálise e semiótica. Psicol. Estud., Maringá, v. 11, n. 2, p. 391-398, 2006. Disponível em: <http://www.scielo.br/scielo.php?script=sci arttext\&pid=S1413-73722006000200018\&lng=en\&nrm=iso\& tlng=pt>. Acesso em: 21 fev. 2010.

BLEICHMAR, N. M.; BLEICHMAR C. L. A psicanálise depois de Freud: teoria e clínica. Porto Alegre: Artes Médicas, 1992.

CHAITIN, G. D. Rhetoric \& culture in Lacan. New York: Cambridge University Press, 1996.

ENKVIST, N. E. Linguística e estilo. São Paulo: Cultrix, 1974.

FIGUEIREDO, L. C. M. Matrizes do pensamento psicológico. 10. ed. Petrópolis, RJ: Vozes, 2003.

FINK, B. O sujeito lacaniano: entre a linguagem e o gozo. Rio de Janeiro: J. Zahar, 1998.

FINK, B. Lacan to the letter. Minneapolis: University of Minnesota Press, 2004.

LACAN, J. A psicanálise e seu ensino (1957). In: Escritos. Rio de Janeiro: J. Zahar, 1998a. p. 496-533.

LACAN, J. Abertura desta coletânea (1966). In: Escritos. Rio de Janeiro: J. Zahar, 1998b. p. 9-11.

MILÁN-RAMOS, J. G. Passar pelo escrito: uma introdução ao trabalho teórico de Jacques Lacan. Campinas: Mercado de letras, 2007.

MILLER, J.-A. Lacan Elucidado. Rio de Janeiro: J. Zahar, 1997.

MILLER, J.-A. Perspectivas do seminário 5 de Lacan. Rio de Janeiro: J. Zahar, 1999.

PIERRAKOS, M. A "batedora" de Lacan. São Paulo: Perspectiva, 2005.

SOKAL, A.; BRICMONT, J. Imposturas intelectuais. Rio de Janeiro: Record, 1999.

SOUZA, P. C. As palavras de Freud: o vocabulário freudiano e suas versões. São Paulo: Ática, 1999.

TURKLE, S. Psychoanalytic politics: Jacques Lacan and Freud's french revolution. $2^{\text {nd }}$ ed. New York: Guilford, 1992.

ŽIŽEK, S. A lâmina de David Lynch. In: FELDSTEIN, R.; FINK, B.; JAANUS, M. (Org.). Para ler o seminário 11 de Lacan: os quarto conceitos fundamentais da psicanálise. Rio de Janeiro: J. Zahar, 1997. p. 220-235.

Recebido em: 12 de outubro de 2012 Aceito em: 2 de julho de 2015 